\title{
CATEGORIA DOCENTE, CONTRATAÇÃO TEMPORÁRIA E PRECARIZAÇÃO DO TRABALHO DO PROFESSOR NA REDE ESTADUAL DE SÃO PAULO
}

\author{
Zelina Cardoso Grund ${ }^{1}$, Cláudia da Mota Darós Parente ${ }^{2}$
}

${ }^{1}$ Mestranda em Educação pela Universidade Estadual Paulista - UNESP, Campus de Presidente Prudente, SP. E-mail: zelina2509@terra.com.br

${ }^{2}$ Doutora em Educação pela Universidade Estadual de Campinas - UNICAMP. Professora do Departamento de Administração e Supervisão Escolar (DASE), Universidade Estadual Paulista - UNESP, Campus Marília, SP. Professora do Programa de Pós-Graduação em Educação, Universidade Estadual Paulista - UNESP, Campus de Presidente Prudente, SP.

\section{RESUMO}

O presente artigo tem como objetivo descrever as diferentes categorias docentes existentes na rede estadual de ensino de São Paulo, discutindo a problemática da contratação temporária e seu reflexo sobre a precarização do trabalho docente. Por meio de pesquisa documental construiu-se um percurso históricolegal do surgimento das diferentes categorias docentes. A partir disso, procedeu-se a uma pesquisa exploratória acerca da quantidade de professores efetivos e não efetivos na rede estadual de ensino. 0 trabalho evidencia a presença de um grande número de professores contratados na rede estadual paulista nos últimos anos, o que traz consequências para a precarização do trabalho docente.

Palavras-chave: educação, professores, contrato de trabalho, precarização, São Paulo

\section{TEACHING CATEGORY, TEMPORARY CONTRACT AND PRECARIOUSNESS OF TEACHER'S WORK IN THE PUBLIC SCHOOL SYSTEM OF SÃO PAULO}

\begin{abstract}
This paper aims to describe the different teaching categories that exist in the public school system of São Paulo, discussing the problem of temporary contracting and its reflection on the precariousness of teaching work. Through documentary research, a historical-legal path was developed for the emergence of different teaching categories. From this, an exploratory research was carried out on the number of effective and non-effective teachers in the public school system of São Paulo. The research evidences the presence of a large number of teachers contracted in the state of São Paulo in recent years, which has consequences for the precariousness of teaching work.
\end{abstract}

Keywords: education, teachers, contract of work, precariousness, São Paulo

\section{INTRODUÇÃO}

Neste trabalho pretende-se destacar dois elementos do trabalho docente na rede estadual de ensino de São Paulo: a quantidade de categorias docentes e a contratação temporária. Esses dois elementos têm causado o chamado "mal-estar" docente, pois, por um lado, não há direitos iguais para as inúmeras categorias e, por outro, o uso continuado e crescente de contratações temporárias tem levado à alta rotatividade de professores nas escolas.

A alta rotatividade de professores nas escolas, resultado, em grande medida, do elevado número de contratações temporárias, é mencionada na pesquisa realizada por Lapo e Bueno (2003, p. 71) e, segundo as autoras, a alta rotatividade limita os vínculos do professor com a escola, o que pode levar a "[...] graves consequências para um tão necessário e almejado ensino de qualidade".

Ao analisar as mudanças que as reformas educacionais acarretaram no processo de flexibilização e de precarização do trabalho docente, Oliveira (2004, p.1.140) afirma que:

$\mathrm{O}$ aumento dos contratos temporários nas redes 
públicas de ensino, chegando, em alguns estados, a número correspondente ao de trabalhadores efetivos, o arrocho salarial, o respeito a um piso salarial nacional, a inadequação ou mesmo ausência, em alguns casos, de planos de cargos e salários, a perda de garantias trabalhistas $\mathrm{e}$ previdenciárias oriunda dos processos de reforma do Aparelho de Estado têm tornado cada vez mais agudo $o$ quadro de instabilidade e precariedade do emprego no magistério público.

No estado de São Paulo, a contratação temporária do profissional docente intensifica-se cada vez mais. Isso pode ser exemplificado por meio da autorização para contratação de 765 professores temporários para a Educação Básica, em maio de 2017, sob a argumentação de que eles seriam necessários para substituição de professores efetivos que se afastam por motivos de saúde ou licença maternidade ${ }^{1}$.

No entanto, é preciso destacar que a contratação temporária na rede pública de ensino paulista tornou-se mais frequente do que os concursos públicos, exigência constitucional para ingresso na carreira do magistério público. A título de ilustração, os últimos concursos públicos ocorreram de forma muito irregular e espaçada: 2003 - concurso para professor de Educação Básica II (Anos Finais do Ensino Fundamental e Ensino Médio) $)^{2} ; 2005$ - concurso para Professor de Educação Básica I e II (Anos Iniciais do Ensino Fundamental, Anos Finais do Ensino Fundamental e Ensino Médio) ${ }^{3} ; 2010$ - concurso para Professor de Educação Básica II (Anos Finais do Ensino
Fundamental e Ensino Médio) $)^{4} ; 2014$ - Professor de Educação Básica II (Anos Finais do Ensino Fundamental e Ensino Médio) $)^{5}$. Conforme o Sindicato dos Professores no Ensino Oficial do Estado de São Paulo (APEOESP), apenas sob pressão da categoria, em 2016, o governador de São Paulo convocou os aprovados no concurso público de $2013^{6}$.

Expostas essas considerações iniciais, o objetivo deste trabalho é descrever as diferentes categorias docentes existentes na rede estadual de ensino de São Paulo, discutindo a problemática da contratação temporária e seu reflexo sobre a precarização do trabalho docente.

Para isso, foi feita uma pesquisa documental, com ênfase na legislação educacional, sobre as diferentes categorias docentes presentes na rede estadual de ensino de São Paulo. Optou-se por fazer um percurso histórico-legal para contextualizar o surgimento das diferentes categorias docentes. A partir disso, procedeu-se a uma pesquisa exploratória acerca da quantidade de professores efetivos e não efetivos na rede estadual de ensino, a fim de evidenciar a presença de um grande número de professores contratados. Os dados quantitativos foram coletados eletronicamente na Secretaria de Educação de São Paulo e fazem referência ao período de 2015 a 2017.

\section{RESULTADOS}

O docente da rede pública de ensino do estado de São Paulo é nomeado para cargo público de provimento efetivo por meio de concurso público de provas ou de provas e títulos, conforme art. 14 da Lei n. 10.261/1968 (SÃO PAULO, 1968) e Lei Complementar $n$. 444/1985, art. 13 (SÃO PAULO, 1985). Além dos professores efetivos existentes, os docentes não efetivos foram agrupados em 8 (oito) categorias, divididos em dois grupos, estáveis e contratados, conforme Quadro 1.

\footnotetext{
${ }^{1}$ Informações

disponíveis

em:

https://publicadoeducacao.wordpress.com/2017/05/29/governode-sao-paulo. Acesso em: 28 maio 2018. Informações

disponíveis em:

http://www.educacao.sp.gov.br/noticias/secretaria-de-educacaoconvoca-mais-de-22-mil-professores-aprovados-em-concurso-de2003/. Acesso em: 28 maio 2018. Informações disponíveis em: http://www.educacao.sp.gov.br/noticias/secretaria-convoca-maisde-16-mil-professores-aprovados-nos-concursos-de-2005/. Acesso em: 28 maio 2018
}

\footnotetext{
4 Informações disponíveis em: https://www.pciconcursos.com.br/concurso/secretaria-de-estadoda-educacao-sp-10083-vagas. Acesso em: 25 jan. 2018

5 Informações disponíveis em: https://documento.vunesp.com.br/documento/stream/NDc0MA\%3 d\%3d. Acesso em: 28 maio 2018. 6 Informações disponíveis em: http://www.redebrasilatual.com.br/educacao/2016/12/governoalckmin-cede-a-pressoes-e-nomeia-professores-aprovados-emconcurso-9355.html. Acesso em: 28 maio 2018.
} 
Quadro1. Categorias docentes - Rede Estadual de Ensino - São Paulo - 1951 a 2017.

\begin{tabular}{ccc}
\hline Efetivos & Estáveis & Contratados \\
\hline Por concurso público & $\mathbf{N}$ & $\mathrm{S}$ \\
& $\mathbf{P}$ & $\mathrm{O}$ \\
& $\mathbf{F}($ OFA) & $\mathrm{V}$ \\
& & $\mathrm{L}$ \\
\hline
\end{tabular}

Fonte: São Paulo (1951; 1974; 2007). Elaborado pelas autoras.

Os docentes da categoria $\mathbf{N}$ foram admitidos pela Lei n. 1.309/1951, art. $1^{\circ}$ que estabelece: "Além dos funcionários poderá haver, no serviço público estadual, pessoal extranumerário, admitido a título precário, para o desempenho de função determinada" (SÃO PAULO, 1951). Esses profissionais foram admitidos no regime da Consolidação das Leis do Trabalho (CLT). Atualmente, há a indicação da existência de apenas 01 (um/a) docente remanescente da categoria $\mathrm{N}$ na Diretoria de Ensino Regional de Jundiaí. Os profissionais da educação dessa categoria adquiriram a estabilidade pelo Ato das Disposições Constitucionais Transitórias (ADCT) da Constituição Federal de 1988 (BRASIL, 1988).

Os professores da categoria $\mathbf{P}$ admitidos pela Lei n. 500/1974, que instituiu o regime jurídico dos servidores admitidos em caráter temporário, foram beneficiados pela garantia da estabilidade, de acordo com o art. 19 de Ato das Disposições Constitucionais Transitórias (ADCT), da Constituição Federal de 1988 (BRASIL, 1988), que estabeleceu

$$
\begin{aligned}
& \text { Art. } 19 \text { - Os servidores } \\
& \text { públicos civis da União, } \\
& \text { dos Estados, do Distrito } \\
& \text { Federal e dos Municípios, } \\
& \text { da administração direta, } \\
& \text { autárquica e das } \\
& \text { fundações públicas, em } \\
& \text { exercício na data da } \\
& \text { promulgação } \\
& \text { Constituição, há pelo } \\
& \text { menos cinco anos } \\
& \text { continuados, e que não } \\
& \text { tenham sido admitidos na } \\
& \text { forma regulada no art. } 37 \text {, } \\
& \text { da Constituição, são } \\
& \text { considerados estáveis no } \\
& \text { serviço público. }
\end{aligned}
$$

Os professores da categoria $F$ (OFA) foram também admitidos pela Lei n. 500/1974, art. 1ㅇ, que indica: "Além dos funcionários públicos poderá haver na administração estadual servidores admitidos em caráter temporário" (SÃO PAULO, 1974). Posteriormente, foram submetidos ao Regime do Plano de Carreira, Vencimentos e Salários para os integrantes do Quadro do Magistério da Secretaria da Educação, na forma da Lei Complementar n. 836/1997 (SÃO PAULO, 1997) e conseguiram a estabilidade com a vigência da Lei Complementar n. 1.010/2007. A referida lei dispõe sobre a criação da São Paulo Previdência (SPPREV), entidade gestora do Regime Próprio de Previdência dos Servidores Públicos (RPPS) e do Regime Próprio de Previdência dos Militares do Estado de São Paulo (RPPM):

Art. 2 - São segurados dos
RPPS e do RPPM do Estado
de São Paulo,
administrados pela
SPPREV:
§ 2o - Por terem sido
admitidos para o exercício
de função permanente,
inclusive de natureza
técnica, e os termos do
disposto no inciso I deste
artigo são titulares de
cargos efetivos os
servidores ativos e inativos
que, até a data da
publicação desta lei
tenham sido admitidos
com fundamento nos
incisos I e II do artigo 10 da
Lei 500, de 13 de
novembro de 1974. (SÃO
PAULO, 2007)

Os docentes da categoria S, admitidos após 17 de julho de 2007, poderiam ser contratados por tempo determinado, mediante a condição de estarem enquadrados na portaria de eventuais na vigência da Lei Complementar $n$. 1.010/2007 (SÃO PAULO, 2007). Os professores e professoras das categorias $\mathbf{O}$ e $\mathbf{L}$ também regidos pela Lei n. 500/1974 (SÃO PAULO, 1974), poderiam ser contratados desde que já estivessem com aulas atribuídas. Ambos estavam 
sujeitos a contratação temporária, Lei Complementar n. 1.093/2009. Além das hipóteses elencadas nos referidos incisos e alíneas, a contratação era "precedida de processo seletivo simplificado [...]" e tinha caráter classificatório (SÃO PAULO, 2009). A categoria V refere-se aos profissionais eventuais, sem aulas atribuídas, admitidos após a Lei n. 1.093/2009.

A categoria L foi extinta em 2011, assim como a categoria I (docentes eventuais) admitidos pela Lei n. 500/1974. O último docente remanescente da categoria L, lotado na Diretoria Regional de Franca, saiu em julho de 2017 da rede de ensino estadual paulista.

Ver-se-á, neste estudo, que a contratação temporária tem sido realizada de maneira contínua no cenário da rede estadual de ensino de São Paulo. O referido mecanismo está previsto na Constituição Federal de 1988, no art. 37, inciso IX, que estabelece: "a lei estabelecerá os casos de contratação por tempo determinado para atender a necessidade temporária de excepcional interesse público" (BRASIL, 1988). A regulamentação veio com a Lei n. 8.745/1993 que dispôs sobre a possibilidade de contratação temporária (BRASIL, 1993).

Em consonância com a Constituição Federal, a Constituição Estadual de São Paulo instituiu a contratação temporária (SÃO PAULO, 1989), efetivando-se ao longo do tempo com a Lei Complementar n. 1.093/2009, que estabelece, no art. 1으, as hipóteses para tal fim. A Lei Complementar n. 1.132/2011 (SÃO PAULO, 2011), alterou a redação do "caput" do art. $7^{\circ} \mathrm{e}$ $\S \S$ da Lei Complementar n. 1.093/2009 (SÃO PAULO, 2009a), passando para "o prazo máximo de até 12 (doze) meses, ressalvada, quanto à vigência, a contratação para função docente, que fica limitada ao ano letivo fixado no calendário escolar", desdobrando-o no § 1 을 com novo texto: "A contratação para o exercício de função docente poderá ser prorrogada até o último dia letivo do ano em que findar o prazo previsto no "caput" deste artigo". A Lei Complementar n. $1.163 / 2012$, acrescenta que "Os contratados para o exercício de função docente [...] poderão celebrar novo contrato de trabalho, cuja vigência fica limitada ao período correspondente ao ano letivo de 2012 [...]" (SÃO PAULO, 2012a).

Pela legislação são garantidos aos docentes contratados direitos amparados pelo Decreto n. 54.682/2009: décimo terceiro salário na proporção de $1 / 12$ (um doze avos) por mês trabalhado ou fração superior a 15 (quinze) dias; o pagamento das férias acrescido de $1 / 3$ (um terço) após decorridos 12 (doze) meses de exercício na função, em caráter indenizatório (art. 17, incisos I, II); as faltas são abonadas, até o limite de 2 (duas) durante o período contratual, não excedendo a uma por mês, não implicando em desconto da remuneração (art. 18, § 20); faltas justificadas, até o limite de 3 (três), durante o período contratual, não excedendo uma por mês (art. 18, § 3ㅇ), excedendo esse limite incorre na rescisão contratual, conforme art. $8^{\circ}$, inciso IV da Lei Complementar n. 1.093/2009 (SÃO PAULO, 2009b). Na Lei Complementar n. 1.093/2009, dentre os direitos garantidos, destaca-se 0 art. 13, que dita: serão consideradas como dias trabalhados as ausências do contratado em virtude de: casamento até 2 (dois) dias consecutivos; falecimento de pais, irmãos, cônjuge, companheiro ou filhos, até 2 (dois) dias consecutivos. O contratado ficará vinculado ao Regime Geral de Previdência Social, art. 20 (SÃO PAULO, 2009a).

A contratação temporária incorre na supressão de benefícios sociais como: adicional por tempo de serviço; evolução funcional; licença-prêmio; afastamento para tratar interesses próprios ou por motivo de doença de pessoa da família, etc., o que provoca o "malestar" e constrangimento à classe trabalhadora docente.

É interessante mencionar que a Lei Complementar n. 1.191/2012, art. 11, revogou o art. 9o da Lei Complementar n. 1.164/2012 que estabelecia, no parágrafo único, a inviabilidade da contratação temporária nos seguintes termos: "Nas Escolas Estaduais de Ensino Médio de Período Integral não será permitida a contratação de professor temporário [...]" (SÃO PAULO, 2012 bc). Com a revogação do referido dispositivo legal, a própria legislação abriu o precedente para processos de seleção dos servidores para contratação temporária nas Escolas Estaduais de Ensino Médio de Período Integral. O procedimento, comum nas redes públicas, desfavorece as relações de trabalho, repercutindo sobre o próprio Estado, que não consegue atingir as metas propostas para um ensino de qualidade.

Nesta mesma perspectiva, o docente deixa de se beneficiar da evolução "em diferentes momentos da carreira", conforme o Plano de Carreira, Vencimentos e Salários para os integrantes do Quadro do Magistério da Secretaria da Educação (SÃO PAULO, 1997). 
Nessas duas situações os professores e professoras contratados são prejudicados e sofrem consequências de ordem funcional, financeira e psicológica. Nada mais é do que deparar-se com "[...] a nova fase de desconstrução do trabalho sem precedentes em toda era moderna, ampliando os diversos modos [...] da precarização do trabalho" (ANTUNES, 2015 , p. 259), o que reflete sobre os direitos sociais.

Exposto o percurso histórico-legal do surgimento das diferentes categorias docentes existentes na rede estadual de ensino de São Paulo, passar-se-á a apresentar os dados relativos ao quantitativo de professores enquadrados em cada uma das classes/categorias, a fim de que seja possível visualizar a grande incidência de docentes contratados na rede.

A Tabela 1 mostra que, gradativamente, algumas categorias das classes docentes estão se extinguindo na rede de ensino estadual paulista, conforme citado anteriormente. Da categoria $\mathrm{N}$ (CLT) existe apenas um(a) professor(a) lotado(a) na Diretoria de Ensino Regional de Jundiaí.
Tabela 1. Professores da rede estadual de São

Paulo, por categoria/classe - agosto/2017.

\begin{tabular}{lll}
\hline Classe/Categoria & \multicolumn{1}{c}{$\mathbf{2 0 1 7}$} & Porcentagem \\
\hline Efetivos & 128.152 & 64,7 \\
\hline Categoria P & 200 & 0,1 \\
\hline Categoria N (CLT) & 1 & 0,0 \\
\hline Categoria F & 43.124 & 21,8 \\
Categoria L & 0 & 0,0 \\
\hline Temporários & 26.567 & 13,4 \\
\hline Total & 198.044 & 100,0 \\
\hline
\end{tabular}

Fonte: São Paulo (2017a). Elaborada pelas autoras.

Pela Tabela 2, nos anos de 2015 e 2016, os dados disponibilizados pela Secretaria de Educação não separam os docentes por categorias, o que impediu de verificar a evolução do número de contratação na rede estadual desse período. A separação por categorias ocorre a partir de 2017, onde sobressai um elevado percentual de $13,4 \%$ de professores contratados.

Tabela 2. Quantidade de Professores da rede estadual de ensino - São Paulo - por classes/categorias docentes - 2015 a agosto 2017.

\begin{tabular}{llcllll}
\hline Classe/Cat. & $\mathbf{2 0 1 5}$ & $\mathbf{\%}$ & $\mathbf{2 0 1 6}$ & $\mathbf{\%}$ & $\mathbf{2 0 1 7}$ & $\mathbf{\%}$ \\
\hline Efetivos & 132.896 & 59,1 & 124.074 & 60,8 & 128.152 & 64,7 \\
Demais Categorias & 91.810 & 40,9 & 80.092 & 39,2 & --- & ---- \\
Categoria P & & & & & 200 & 0,1 \\
Categoria N & & & & & 1 & 0,0 \\
Categoria F & & & & & 43.124 & 21,8 \\
Temporários & & & & & 26.567 & 13,4 \\
Total & 224.706 & 100,0 & 204.166 & 100,0 & 198.044 & 100,0 \\
\hline
\end{tabular}

Fonte: São Paulo (2015; 2016; 2017a). Elaborada pelas autoras.

Na tabela 3 observa-se que, de fevereiro a novembro de 2017, há uma ascensão na contratação temporária, exceto no mês de julho, mês em que houve um decréscimo de 1.423 (um mil, quatrocentos e vinte e três) profissionais. Note-se ainda que de janeiro para fevereiro houve o desligamento em massa de 13.157 (treze mil, cento e cinquenta e sete) professores da rede de ensino. Isso caracteriza uma evidente precarização do trabalho docente, situação que nos remete às palavras de Alves (2005, p. 259): uma "nova exclusão social, caracterizada pelo desemprego".

Tabela 3. Quantidade de professores temporários da rede estadual de ensino - São Paulo - Janeiro a Novembro/2017.

\begin{tabular}{llllllllllll}
\hline Categ. Fun & Jan. & Fev. & Mar. & Abr. & Maio & Jun. & Jul. & Ago. & Set. & Out. & Nov. \\
\hline Temporári & 30.60 & 17.44 & 21.40 & 22.92 & 24.74 & 24.97 & 23.55 & 26.56 & 27.53 & 27.93 & 28.32 \\
os & 6 & 9 & 3 & 1 & 6 & 8 & 5 & 7 & 8 & 2 & 9 \\
\hline
\end{tabular}

Fonte: São Paulo (2017b). Elaborada pelas autoras. 


\section{DISCUSSÃO}

A precarização, de modo geral, não é um assunto novo no mundo do trabalho. No Brasil, a reestruturação produtiva exigida pelo ideal neoliberal, levou à precariedade de emprego e de salário. De acordo com Alves (2005, p. 265),

$$
\begin{aligned}
& \text { A adoção de uma } \\
& \text { flexibilização do contrato } \\
& \text { de trabalho, cuja } \\
& \text { expressão jurídica é a Lei } \\
& \text { do Contrato Temporário, } \\
& \text { tende a constituir um } \\
& \text { estatuto salarial precário } \\
& \text { para amplas parcelas da } \\
& \text { classe trabalhadora, } \\
& \text { expondo-a, cada vez mais, } \\
& \text { à disposição das } \\
& \text { idiossincrasias do capital. }
\end{aligned}
$$

Na educação, o quadro não é diferente, o que tem levado a um estudo sistemático por parte de pesquisadores sobre $\mathrm{o}$ assunto. A problemática da precarização no sistema educacional é destacada no presente artigo, em razão das condições de trabalho oferecidas aos profissionais docentes nos últimos anos. Conforme Novaes (2009, p. 19),

$$
\begin{aligned}
& \text { Desde a segunda metade } \\
& \text { dos anos 90, os } \\
& \text { profissionais da educação } \\
& \text { da rede estadual paulista } \\
& \text { têm sofrido os impactos } \\
& \text { da política educacional } \\
& \text { empreendida pela SEE/SP } \\
& \text { no que diz respeito às } \\
& \text { precárias condições de } \\
& \text { trabalho e organização da } \\
& \text { escola, traduzidas na } \\
& \text { elevada razão professor/ } \\
& \text { aluno, na ausência de um } \\
& \text { projeto consistente de } \\
& \text { formação em serviço, na } \\
& \text { manutenção de processos } \\
& \text { de itinerância e e } \\
& \text { rotatividade dos } \\
& \text { professores, ocasionado } \\
& \text { por um processo } \\
& \text { anacrônico de atribuição } \\
& \text { de aulas, no elevado } \\
& \text { absenteísmo docente, } \\
& \text { além da responsabilização } \\
& \text { individual dos professores } \\
& \text { pelo fracasso escolar dos } \\
& \text { alunos. }
\end{aligned}
$$

Nesta mesma perspectiva, destacam-se situações originadas pela perda salarial, o que leva à necessidade de dupla jornada, oferecida pela legislação brasileira, de acordo com palavras de Duarte (2011, p. 172),

\begin{abstract}
No Brasil, os professores da educação básica, no setor público, não são funcionários de Estado, pois não se trata de um trabalho de dedicação exclusiva. Os docentes podem trabalhar em mais de uma rede ao mesmo tempo (estadual, municipal ou privada), ou mesmo dobrar o turno em uma mesma rede.
\end{abstract}

É notório que as políticas públicas educacionais têm como pressuposto assegurar a qualidade de ensino. Por outro lado, essas mesmas políticas públicas provocam situações impactantes, que levam à precarização. No que concerne à prática pedagógica cotidiana sobressaem alguns pontos, que convergem com a precarização do trabalho docente:

- o número excessivo de unidades escolares a que o profissional se submete para completar a sua carga horária, comprometendo o ensino e aprendizagem de qualidade;

- a submissão a um quadro de horário que pode ser fracionado, impondo a permanência do profissional na escola, que ocasiona as chamadas "horas vazias";

- os contratos temporários com possíveis consequências no quadro do magistério;

- o processo crescente de atividades atribuídas ao docente, o que provoca um ritmo acelerado de trabalho no cotidiano escolar.

Aliás, a imposição de novas atribuições ao trabalho docente passaram a fazer parte do cotidiano da vida do profissional da educação, em especial dos professores e professoras. Com isso "a distância entre a idealização da profissão e a realidade de trabalho tende a aumentar, em razão da complexidade e da multiplicidade de tarefas que são chamados a cumprir nas escolas" (GATTI; BARRETO; ANDRÉ, 2011, p. 25).

Tudo isso causa prejuízos e "mal-estar docente" ao profissional, refletindo de forma negativa na sua vida. Esteve (1999, p. 98), ao tratar do "mal-estar docente" afirma que esses "efeitos permanentes, de carácter negativo, que 
afetam a personalidade do professor como resultado das condições psicológicas e sociais em que exerce a docência, devido à mudança social acelerada".

De acordo com Oliveira (2004, p. 1132),

O professor, diante das variadas funções que a escola pública assume, tem de responder a exigências que estão além de sua formação. Muitas vezes esses profissionais são obrigados a desempenhar funções de agente público, assistente social, enfermeiro, psicólogo, entre outras. Tais exigências contribuem para um sentimento de desprofissionalização, de perda de identidade profissional, da constatação de que ensinar às vezes não é o mais importante (Noronha, 2001). Essa situação é ainda mais reforçada pelas estratégias de gestão já mencionadas, que apelam ao comunitarismo e voluntariado, na promoção de uma educação para todos. Nesse contexto é que se identifica um processo de desqualificação desvalorização sofrido pelos professores. As reformas em curso tendem a retirar deles a autonomia, entendida como condição de participar da concepção e organização de seu trabalho.

Para Cortesão (2002, p. 30), “o "malestar" na escola é uma realidade que, nos diferentes níveis de ensino, tem realmente vindo a aumentar". A situação tem levado ao número crescente dos processos de abandono do cargo e à exoneração.

Nesse processo de precarização, a intensificação da jornada de trabalho pode acarretar um processo de adoecimento, que inclui enfermidades como gastrite, insônia, pressão alta, depressão e outras sequelas. Há alguns fatores que contribuem para isso, a exemplo das "horas in itinere", quando do deslocamento entre uma unidade escolar e a outra, no caso do docente que precisa assumir aulas em três e até quatro escolas, em diferentes municípios, para completar a sua jornada de trabalho.

Outro aspecto a ponderar é o quadro de horário proposto por algumas escolas, em que desconsidera o intervalo intrajornada, o que acarreta a indisponibilidade de tempo adequado para o almoço. Por vezes, os docentes têm de se submeter a um intervalo de apenas 10 (dez) minutos, ocasionando prejuízo à saúde.

Feitas tais considerações sobre a precarização do trabalho docente, neste trabalho, pretendeu-se evidenciar que a diversidade de categorias docentes também leva a uma diversidade de garantias e direitos dos profissionais da educação. O percurso históricolegal mostrou que, embora a contratação temporária esteja devidamente prevista e regulamentada, o uso que se tem feito dela pode ser considerado abusivo.

Cabe destacar que, no que se refere ao processo de contratação dos professores da categoria $\mathrm{O}$ (temporários), a Lei Complementar $\mathrm{n}$. 1.093 , art. $6^{\circ}$, definiu que "É vedada, sob pena de nulidade, a contratação da mesma pessoa, com fundamento nesta lei complementar, ainda que para atividades diferentes, antes de decorridos 200 (duzentos) dias do término do contrato" (SÃO PAULO, 2009a). Esse mecanismo, conhecido como "duzentena", dispõe sobre a necessidade do afastamento do professor entre o término de um contrato e o início do outro por um período de 200 (duzentos) dias. Em virtude de reclamações generalizadas sobre a "duzentena" por parte dos trabalhadores, devido às graves consequências sobre a vida dos profissionais da educação - ainda que o próprio contrato de trabalho já tenha seu caráter de precarização - foi promulgada a Lei Complementar n. 1.277/2015 que, no seu artigo 1ㅇ, acrescentou os $\S \S 10$ e 2 의 ao artigo 60 da Lei Complementar n. 1.093/2009. No $\S 10$ reduz para 180 (cento e oitenta) dias o prazo de afastamento entre o término de um contrato e início do outro; no $\S 2$ o o prazo é reduzido para 30 (trinta) dias, quando se tratar de contratados docentes indígenas (SÃO PAULO, 2015).

Recentemente, foi aprovada Lei Complementar n. 1.314/2017 reduzindo o prazo de afastamento do professor entre contratos passando de 180 (cento e oitenta) para 40 (quarenta) dias no ano letivo 2018: 
Fica excepcionalmente reduzido para 40 (quarenta) dias, no ano letivo de 2018(grifo nosso), 0 prazo estabelecido no $\S 1$ 의 do artigo 60 para celebração donovo contrato de trabalho pelos docentes contratados nos termos destaLei Complementar". (SÃO PAULO, 2017)

No texto da lei fica evidente que a proposta da redução do limite de 180 (cento e oitenta) para 40 (quarenta) dias vem atender a uma situação emergencial, pois alunos correm o risco de ficar sem aula.

Isso significa que a redução do prazo para a contratação temporária não é definitiva e poderá ser novamente desconsiderada no próximo ano, provocando insegurança à classe docente.

Enfim, a contratação temporária vem se apresentando de maneira expressiva na rede de ensino em alguns estados brasileiros, a exemplo do estado de São Paulo, conforme evidenciou o presente artigo. A implementação dessas políticas públicas, sob o manto da legalidade, têm se acentuado na área da educação e, consequentemente, no trabalho docente. 0 espaço escolar passou a ser dividido entre dois tipos de profissionais: os que possuem a estabilidade com a garantia da incorporação de todos os direitos aos proventos da aposentadoria; e, aqueles que a cada ano ficam sujeitos a fazer parte do quadro dos itinerantes, imersos numa situação de incerteza.

Essa prática de contratação temporária, de autêntico e exclusivo cunho econômico, se naturalizou na rede de ensino, a exemplo do novo Edital de Convocação para a Realização do Processo Seletivo Simplificado na rede estadual, em $2017^{7}$. Tal prática mostra-se incoerente com uma das metas do próprio estado de São Paulo, constante do "Programa Educação Compromisso de São Paulo", instituído pelo Decreto n으 $57.571 / 2011$, que é de "valorizar e investir no desenvolvimento do capital humano da Secretaria da Educação do Estado de São Paulo", ocasionando consequências ao corpo docente, às condições de trabalho, rumo à precarização (SÃO PAULO, 2011).

\section{REFERÊNCIAS}

ALVES, G. O novo (e precário) mundo do

trabalho. São Paulo: Boitempo Editorial, 2005.

ANTUNES, R. Os sentidos do trabalho. 2. ed. São

Paulo: Boitempo Editorial, 2015.

BRASIL. Constituição federal de 1988. Disponível em:

<http://www.planalto.gov.br/ccivil_03/constituic ao/constituicaocompilado.htm $>$. Acesso em: 02 jun. 2017.

BRASIL. Lei n. 8.745, de 9 de dezembro de 1993. Dispõe sobre a contratação por tempo determinado. Disponível em: <http://www.planalto.gov.br/ccivil_03/leis/L8745 cons.htm>. Acesso em: 02 de jun. de 2017. Acesso em: 05 set. 2017.

CORTESÃO, L. Ser professor: um ofício em risco de extinção? São Paulo: Cortez, 2002.

DUARTE, A. Políticas educacionais e o trabalho docente na atualidade: tendências e contradições. In: OLIVEIRA, D; DUARTE, A. Políticas públicas e educação: regulação e conhecimento. Belo Horizonte, MG: Fino Traço, 2011. p. 161-182.

ESTEVE, J. M. Os professores perante a mudança social: o mal-estar docente. In: NÓVOA, A.

Profissão Professor. 2 ed. Porto, Portugal: Porto Ed., 1999. p. 93-98.

GATTI, B. A.; BARRETO, E. S. de S; ANDRÉ, M. E. D. de A. Políticas docentes no Brasil: um estado de arte. Brasília: UNESCO, 2011.

LAPO, F. R.; BUENO, B. O. Professores, desencanto com a profissão e abandono do magistério. Cadernos de Pesquisa, São Paulo, $n$. 118, p. 65-88, mar. 2003. Disponível em: <http://www.scielo.br/pdf/cp/n118/16830.pdf> Acesso em: 25 jan. 2018.

NOVAES, L. C. Os impactos da política educacional paulista na prática docente e na organização do trabalho pedagógico nas escolas estaduais paulistas na perspectiva dos 
professores. Jornal de Políticas Educacionais, Curitiba, n. 5, p. 13-26, jan./jun. 2009.

OLIVEIRA, D. A. A reestruturação do trabalho docente: precarização e flexibilização. Educação e Sociedade, Campinas, v. 25, n. 89, p. 1127-1144, set./dez. 2004. Disponível em:

http://www.scielo.br/pdf/es/v25n89/22614.pdf. Acesso em: 25 jan. 2018.

SÃO PAULO. Lei 1.309, de 29 de novembro de 1951. Estabelece o regime jurídico do pessoal extranumerário do serviço público civil, em execução ao disposto no artigo $103 \mathrm{da}$ Constituição do Estado. Disponível em: <https://governosp.jusbrasil.com.br/legislacao/225096/lei-130951>. Acesso em: 05 set. 2017.

SÃO PAULO. Lei n. 10.261, de 28 de outubro de 1968. Dispõe sobre o estatuto dos funcionários públicos civis do Estado. Disponível em:

<http://www.al.sp.gov.br/repositorio/legislacao/l ei/1968/lei-10261-28.10.1968.html>. Acesso em: 10 set. 2017.

SÃO PAULO. Lei $\mathbf{n} . \mathbf{5 0 0}$, de 13 denovembro de 1974. Institui o regime jurídico dos servidores admitidos em caráter temporário. Disponível em: <http://www.al.sp.gov.br/repositorio/legislacao/l ei/1974/lei-500-13.11.1974.html>. Acesso em: 05 set. 2017.

SÃO PAULO. Lei Complementar n. 444, de 27 de dezembro de 1985. Dispõe sobre o Estatuto do Magistério Paulista e dá providências correlatas. Disponível em:

<http://www.al.sp.gov.br/repositorio/legislacao/l ei.complementar/1985/lei.complementar-44427.12.1985.html>. Acesso em: 03 jun. 2017.

SÃO PAULO. Constituição Estadual, de 05 de outubro de 1989. Disponível em: <http://www.al.sp.gov.br/repositorio/legislacao/ constituicao/1989/compilacao-constituicao-005.10.1989.html>. Acesso em: 03 jul. 2017.

SÃO PAULO. Lei complementar n. 836, de 30 de dezembro de 1997. Plano de carreira, vencimentos e salários para os integrantes do quadro do magistério da secretaria da Educação. Disponível em:

<http://www.al.sp.gov.br/repositorio/legislacao/l ei.complementar/1997/lei.complementar-83630.12.1997.html>. Acesso em: 03 maio 2017.

SÃO PAULO. Lei complementar $\mathbf{n}$ 1.010, de 01 de junho de 2007. Dispõe sobre a criação da SÃO PAULO PREVIDÊNCIA - SPPREV, entidade gestora do Regime Próprio de Previdência dos Servidores Públicos - RPPS e do Regime Próprio de Previdência dos Militares do Estado de São Paulo - RPPM. Disponível em:

<https://www.al.sp.gov.br/repositorio/legislacao /lei.complementar/2007/lei.complementar-101001.06.2007.html>. Acesso em: 10 set. 2017.

SÃO PAULO. Lei Complementar n. 1.093, de 16 de julho de 2009a. Dispõe sobre a contratação por tempo determinado de que trata o inciso $X$ do artigo 115 da Constituição Estadual. Disponível: <http://www.al.sp.gov.br/repositorio/legislacao/l ei.complementar/2009/lei.complementar-109316.07.2009.html>. Acesso em: 10 set. 2017.

SÃO PAULO. Decreto n. 54.682, de 11 de agosto de 2009b. Regulamenta a Lei Complementar no 1.093, de 16 de julho de 2009, que dispõe sobre a contratação por tempo determinado. Disponível em:

<http://www.al.sp.gov.br/repositorio/legislacao decreto/2009/decreto-54682-13.08.2009.html>. Acesso em: 10 maio 2017.

SÃO PAULO. Lei Complementar n. 1.132, de 10 de fevereiro de 2011. Altera a Lei Complementar no 1.093, de 2009, que dispõe sobrecontratação por tempo determinado. Disponível em: <http://www.al.sp.gov.br/repositorio/legislacao/l ei.complementar/2011-1.132-10.02.2011.html>. Acesso em: 30 set. 2017.

SÃO PAULO. Lei Complementar n. 1.163, de 04 de janeiro de 2012a. Altera a Lei Complementar no 1.093, de 2009, que dispõe sobre contratação por tempo determinado de que trata o inciso $X$ do artigo 115 da Constituição Estadual. Disponível em:

<https://www.al.sp.gov.br/repositorio/legislacao /lei.complementar/2012/lei.complementar-116304.01.2012.html>. Acesso em: 25 jan. 2018.

SÃO PAULO. Lei Complementar n. 1.164, de 04 de janeiro de 2012b. Institui o Regime De Dedicação Plena e Integral - RDPI e a Gratificação de Dedicação Plena e Integral - GDPI aos 
integrantes do quadro do Magistério em exercício nas escolas estaduais de ensino médio de período integral [...]. Disponível em: <http://www.al.sp.gov.br/repositorio/legislacao/ decreto/2012/decreto-58140-15.06.2012.html>. Acesso em: 04 maio 2017.

SÃO PAULO. Lei Complementar n. 1.191, de 28 de dezembro de 2012c. Dispõe sobre o Programa Ensino Integral em escolas públicas estaduais e altera a Lei Complementar no 1.164, de 2012, que instituiu o Regime de Dedicação Plena e Integral RDPI e a Gratificação de dedicação plena e integral - GDPI [...]. Disponível em: <https://www.al.sp.gov.br/repositorio/legislacao /lei.complementar/2012/lei.complementar-119128.12.2012.html>. Acesso em: 25 jan. 2018.

SÃO PAULO. Lei Complementar n. 1.277, de 22 de dezembro de 2015. Altera a Lei Complementar no 1.093 , de 16 de julho de 2009, que dispõe sobre a contratação por tempo determinado [...]. Disponível em:

<https://www.al.sp.gov.br/repositorio/legislacao /lei.complementar/2015/lei.complementar-127722.12.2015.html>. Acesso em: 25 jan. 2018.

SÃO PAULO. Lei Complementar n. 1.314, de 28 de dezembro de 2017. Altera a Lei Complementar no 1.093, de 16 de julho de 2009, que dispõe sobre a contratação por tempo determinado de que trata o inciso $X$ do artigo 115 da Constituição Estadual. Disponível em:

<https://www.al.sp.gov.br/repositorio/legislacao /lei.complementar/2017/lei.complementar-131428.12.2017 >.html Acesso em: 25 jan. 2018.

SÃO PAULO. Decreto n. 57.571, de 02 de dezembro de 2011. Institui, junto à Secretaria da Educação, o Programa Educação - Compromisso de São Paulo e dá providências correlatas.

Disponível em:

<https://www.al.sp.gov.br/repositorio/legislacao /decreto/2011/decreto-57571-02.12.2011.html>. Acesso em: 25 jan. 2018.

SÃO PAULO. Histórico do Contingente Docente, por cargo e categoria. Agosto, 2017a.

Disponível em:

http://www.educacao.sp.gov.br/cgrh/wpcontent/uploads/2017/09/2.1-

Historico_Contingente-_Docentes_Cargo-x-

Categoria_0817_N.pdf. Acesso em: 28 maio 2018.
SÃO PAULO. Histórico do Contingente Docente, por cargo e categoria. Novembro, 2017b. Disponível em: http://www.educacao.sp.gov.br/cgrh/wpcontent/uploads/2017/12/2.1-

Historico_Contingente-_Docentes_Cargo-xCategoria_1117_N.pdf. Acesso em: 28 maio 2018.

SÃO PAULO. Classes Docentes - Contingente Ativo da Rede Estadual de Ensino. Dezembro, 2015. Disponível em:

http://www.educacao.sp.gov.br/cgrh/wpcontent/uploads/2015/07/3.4-Classes-DocentesSexo-x-Categoria_0615.pdf. Acesso em: 28 maio 2018.

SÃO PAULO. Classes Docentes - Contingente Ativo da Rede Estadual de Ensino. Dezembro, 2016. Disponível em:

http://www.educacao.sp.gov.br/cgrh/wpcontent/uploads/2017/01/3.2-Classes-DocentesCargo-x-Categoria_1216.pdf. Acesso em: 28 maio 2018.

SÃO PAULO. Classes Docentes - Contingente Ativo da Rede Estadual de Ensino. Abril, 2017b. Disponível em:

http://www.educacao.sp.gov.br/cgrh/wpcontent/uploads/2017/05/3.3-Classes-DocentesFaixa-Etária_0417.pdf. Acesso em: 28 maio 2018.

Recebido para publicação em: 19/10/2017 Revisado em: 01/11/2017

Aceito em: 28/01/2018 